\title{
Clarification of Psychological Change and Development in Stressful Situations
}

\author{
Liyang Zhang, Koichiro Aoki, Chieko Kato \\ Graduate School of Information Sciences and Arts, Toyo University, Saitama, Japan \\ Email: s3B101900068@toyo.jp
}

How to cite this paper: Zhang, L. Y., Aoki, K., \& Kato, C. (2021). Clarification of Psychological Change and Development in Stressful Situations. Open Journal of Social Sciences, 9, 364-377.

https://doi.org/10.4236/jss.2021.91027

Received: December 28, 2020

Accepted: January 25, 2021

Published: January 28, 2021

Copyright (c) 2021 by author(s) and Scientific Research Publishing Inc. This work is licensed under the Creative Commons Attribution International License (CC BY 4.0).

http://creativecommons.org/licenses/by/4.0/

(c) (i) Open Access

\begin{abstract}
Previous studies about stress suggested that stressors are associated with positive feelings when they are regarded as "challenge". In such cases, the stressors can contribute to one's mental health as eustress related to positive feelings and healthy physical states. This study conducted a questionnaire in the form of free description focusing on people's awareness of stress and mental and physical stress responses. The purpose of this study is to clarify characteristics of stressful situations which lead to positive psychological change and development by analyzing descriptive data. Free description acquired from the questionnaire was analyzed by means of co-occurrence network and self-organizing maps. The analysis of the free-description revealed the characteristics of eustress and distress, stress regarded as threat or challenge, and thoughts, behaviors, and situations in the process of changing the evaluation of stress. From the results of analysis, it can be said that even in a stress situation that feels like a "threat", the situation can be re-evaluated as a "challenge" by causing a positive psychological transformation that raises confidence in problem solving.
\end{abstract}

\section{Keywords}

Psychological Stress, Eustress/Distress, Stress Response, Text Mining

\section{Introduction}

Stresses people experience in daily life are one of factors causing mental health problems. According to Comprehensive Survey of Living Conditions in Japan (Ministry of Health, Labour and Welfare, 2019), 47.9\% of respondents had troubles and stresses in daily life. About $50 \%$ of males and about $60 \%$ of females had troubles and stresses, especially among the respondents in their thirties to fifties, which suggested necessity of dealing with the mental health problem in Japan. 
The guidelines of maintenance and improvement of mental health for workers (Ministry of Health, Labour and Welfare, 2006) showed the importance of selfcare, which means workers' understanding of their stresses and mental health, preventing, reducing, and coping with their stress, as one of the "four mental health cares" which need to be promoted. It is necessary not only for workers but also all people to understand the mechanism of occurrence of mental and physical health problems as stress responses and take proper measures.

Meaning of the word "stress" includes stressors themselves causing specific mental and physical responses and these stress responses. In the stress-related research field in psychology and physiology there were many studies on the mechanism of mental and physical stress responses due to stressors. Although current mental health care focus on stress reduction, the previous studies showed that stress responses do not necessarily have a bad influence on mind and body. The advocate of stress theory, Hans Selye distinguished two kinds of stressors: eustress which is related to positive feelings and healthy physical states and distress which is related to negative feelings and unstable physical states (Selye, 1974; Lazarus, 1993). It is important to identify if one's stress is eustress or distress and understand causes of these stresses for dealing with one's stress.

In the psychological field a process of evaluation of stressors was assumed as a mechanism influencing whether one's stress is eustress or distress. According to the psychological stress model by Lazarus \& Folkman (1984), implicit stressors are regarded as "irrelevant", "benign-positive", or "stressful" depending on whether the stressors threaten one's value, goal, or belief (primary appraisal). Situations which have no influence on him/her are regarded as "irrelevant". Situations which maintain or improve one's positive states are "benign-positive", and situations which threaten one's values, goals, or beliefs are "stressful". In addition, a stressful situation is classified into "harm/loss", "threat", and "challenge". Situations in which one has suffered a psychological loss are regarded as "harm/ loss". In case that one has not yet suffered the loss, however, he/she may be going to suffer it afterwards, this situation is regarded as "threat". In contrast, if one is confident in overcoming a stressful situation, this situation is regarded as "challenge". The situation of "threat" is characterized by negative feelings such as fear, anxiety, and angry as well as the situation of "challenge" is related to positive feelings such as enthusiasm, excitement, and cheerfulness (Lazarus \& Folkman, 1984). When one challenges are stressful situation, he/she imagines joy and rewards of success and has positive feelings. On the other hand, when one regarded the stressful situation as threat, he/she has negative feelings due to fear of failure (Lazarus \& Folkman, 1984).

Knowledge of previous studies suggested that stressors are associated with positive feelings when they are regarded as "challenge". In such cases, the stressors can contribute to one's mental health as eustress. Furthermore, there were some cases that stressful situations brought positive results such as a tend-and-befriend response (Taylor et al., 2000) which means heightened seeking of relationships 
with others in the stressful situation and post-traumatic growth (PTG; Tedeschi \& Calhoun, 1996) which means positive psychological change of people who have experienced critical situations such as disasters. Mental health care can be conducted more effectively by focusing not only on reduction of stressors and stress responses but also psychological change and development through stress. Therefore, it is necessary to clarify the mechanism of the positive change and development in stressful situations. Since previous studies (Lazarus \& Folkman, 1984) mainly conducted questionnaires about stress responses, there is room for a detailed consideration about the above mechanism through analysis of freedescription.

This study conducted a questionnaire in the form of free description focusing on people's awareness of stress and mental and physical stress responses. The purpose of this study is to clarify characteristics of stressful situations which lead to positive psychological change and development by analyzing descriptive data.

\section{Method}

\subsection{Survey Date and Participants}

A survey was conducted on eight graduate students of A-university (four males and four females in their twenties to fifties) in November 2020. These participants were selected because they are people of various ages.

\subsection{Procedure of Survey}

A questionnaire was conducted in a classroom of the graduate school. The participants took a class about psychological stress model, evaluation of stressful situations (harm/loss, threat, and challenge), and mental and physical stress responses before the participation in the questionnaire. After the class, they were asked to answer the following questions (Table 1) about stress in the form of free description.

Table 1. Questions about stress.

1. Eustress: Please give an example of stress bringing good results (e.g., "high performance was extracted," "stress led to development") and write about your mental and physical states, thoughts, and feelings at that time.

2. Distress: Please give an example of stress bringing bad results (e.g., "performance was lowered," "I lost confidence") and write about your mental and physical states, thoughts, and feelings at that time.

3. Stress regarded as threat: What situation do you think is "threat" among stressful situations? Please recall your experiences and write about characteristics of the situation, your thoughts, and behavior when you feel stressful situation as "threat".

4. Stress regarded as challenge: What situation do you think is "challenge" among stressful situations? Please recall your experiences and write about characteristics of the situation, your thoughts, and behavior when you feel stressful situation as "challenge".

5. Change of evaluation of stress: Do you have experiences of change of feeling about situations from "threat" to "challenge"? If you have, please write about characteristics of the situation, your thoughts, and behavior at that time. 


\subsection{Analysis Method}

Free description acquired from the questionnaire was transcribed and each answer to the above questions was analyzed respectively. The software "KH Coder (Higuchi, 2016, 2017)" was used for text mining. After morphological analysis was conducted as preprocessing for text data, co-occurrence network and selforganizing maps were performed. The results of the questionnaire were discussed based on the co-occurrence network images and the self-organizing maps made by the above methods.

\subsubsection{Co-Occurrence Network Analysis}

Co-occurrence network analysis is a method for representing co-occurrence relationships between words. In co-occurrence network image, words which are similar in their occurrence pattern are linked to each other among extracted words from text data. More frequent words are expressed by larger circles and stronger co-occurrence relationships are expressed by bold lines. In addition, words which belong to the same cluster are expressed by the same color as a result of clustering based on the occurrence pattern of the words.

\subsubsection{Self-Organizing Maps}

Self-organizing maps (SOM) is one of artificial neural networks and this method maps input data to optional dimensions by means of unsupervised learning. In this study, two-dimensional maps composed of hexagonal lattices (neuron) were made as a result of SOM. Each word was placed in any neuron and words whose occurrence patterns were similar were located in neurons nearby. In addition, a result of clustering based on characteristics of each neuron was expressed by different colors.

\section{Results and Discussion}

\subsection{Eustress}

Figure 1 and Figure 2 show a co-occurrence network image and a self-organizing map created using free-description about "eustress". In addition, Japanese-English translation for these figures was shown in Table 2. Focusing on the co-occurrence network image, the stress situations include "match", "announcement", and "examination", and the psychological states at that time include "tension" and "confidence". In particular, the word "tension" is associated with the word "good", suggesting that the respondents themselves positively perceive the tension they felt. In the self-organizing map, "announcement" and "tension", "confidence" and "preparation", and "result" form the same cluster. The former seems to be a performance in a tense state, and the latter is a group of words related to the process of gaining self-confidence.

Even in a stressful situation, tension as a stress reaction occurs in situations such as sports games, presentation of research results, academic examinations, etc., where one challenges a goal set by oneself. It is thought that moderate tension in the challenging scene brought about positive effects such as improvement 


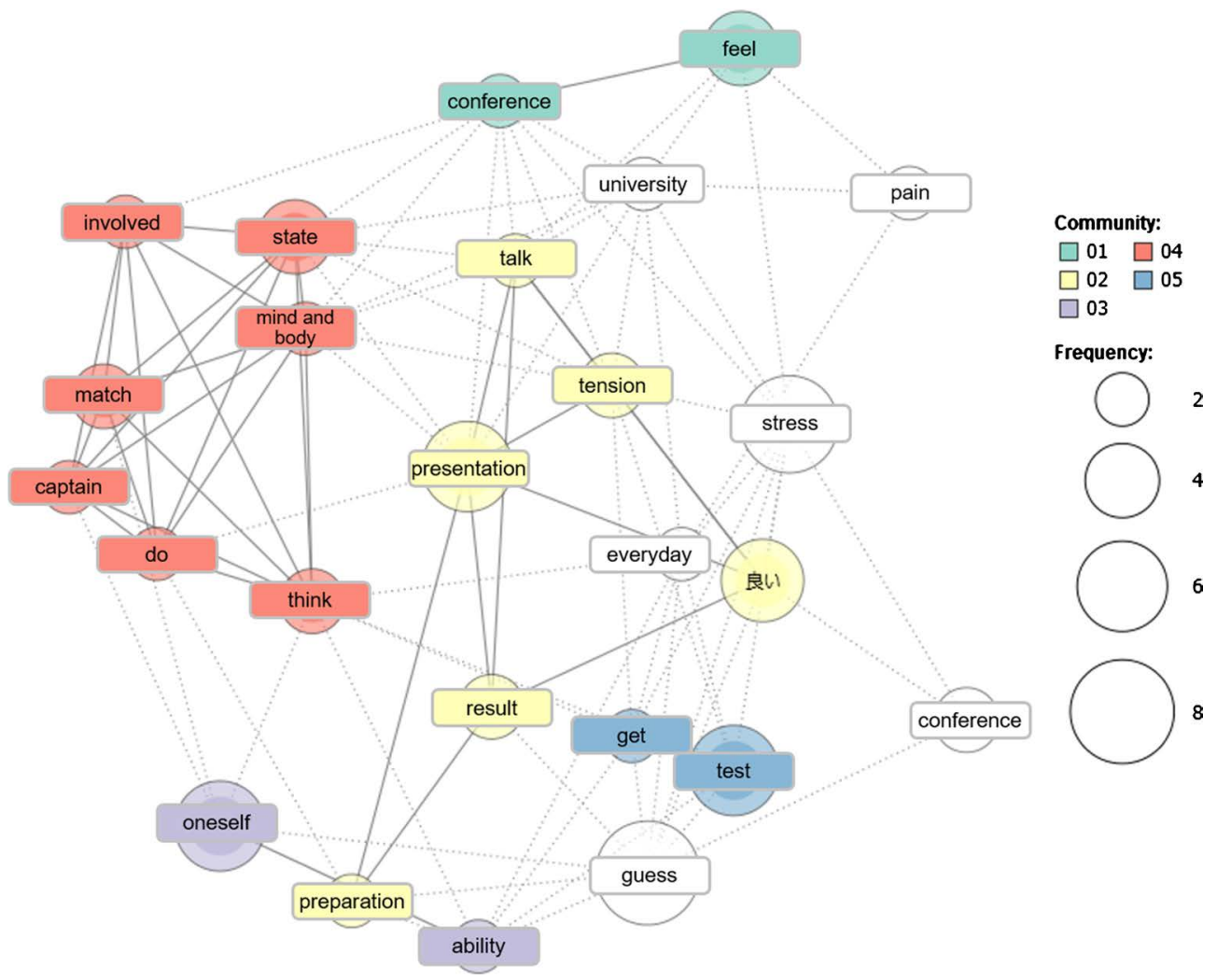

Figure 1. Co-occurrence network image based on free-description about eustress.

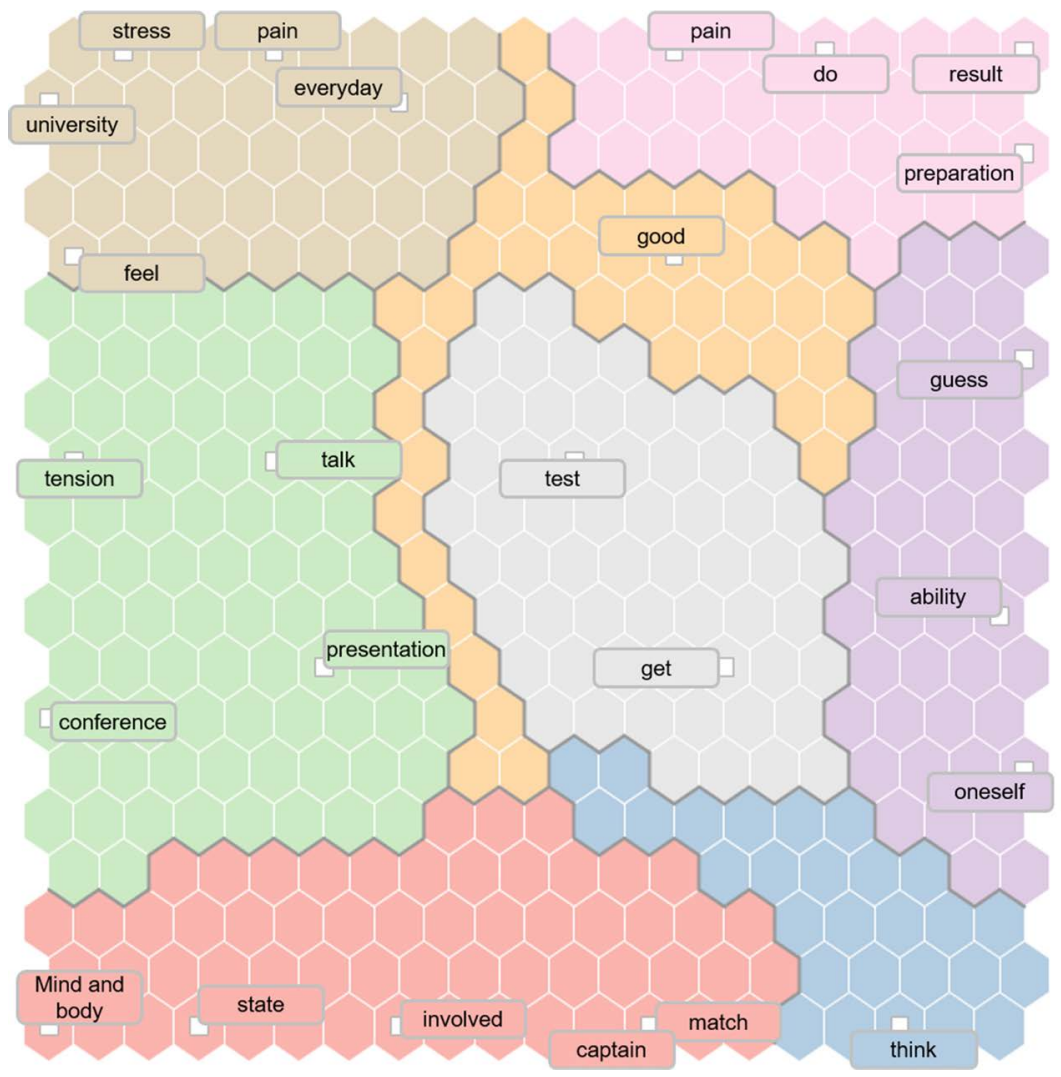

Figure 2. Self-organizing map based on free-description about eustress. 
Table 2. Japanese-English Translation for Figure $1 \&$ Figure 2.

\begin{tabular}{cccccc}
\hline Japanese & English & Japanese & English & Japanese & English \\
\hline 学会 & conference & 大将 & captain & 準備 & preparation \\
感じる & feel & 行う & do & 取る & get \\
大学 & university & 考える & think & 試験 & test \\
痛み & pain & 話す & talk & 自信 & confidence \\
ストレス & stress & 緊張 & tension & 思う & guess \\
関わる & involved & 発表 & presentation & 自分 & oneself \\
状態 & state & 毎日 & everyday & 能力 & ability \\
心身 & mind and body & 良い & good & & \\
試合 & match & 結果 & result & & \\
\hline
\end{tabular}

of concentration and led to the performance. In addition, by making sufficient preparations in advance, you can confidently face situations that involve tension such as exams and games. Alternatively, the experience of overcoming difficulties can lead to confidence gain and can be reflected as a good stress experience. From the above, the following two points can be mentioned as the characteristics of the situation where stress brings about good results. The first point is that by challenging one's own goals, a sense of tension is created in a good way, leading to improved performance. The second point is that the experience of getting into production with sufficient preparation or overcoming difficult situations leads to self-confidence and positively views the stress situation.

\subsection{Distress}

Figure 3 and Figure 4 show a co-occurrence network image and a self-organizing map created using free-description about "distress". In addition, Japanese-English translation for these figures was shown in Table 3. Focusing on the co-occurrence network image, "work" was mentioned as the word indicating stress status, and "depression", "anxiety", "tension", "calmness", and "concentration" were mentioned as the words indicating psychological states. In particular, "calm" and "concentrate" were used negatively in the form of "restless" and "unable to concentrate" in the answers. Among the above words, "anxiety" forms a network with many words, and anxiety about whether or not the stress situation faced can be overcome may lead to a negative psychological state. Also, "tension" is associated with the word "mistake", suggesting that tension causes poor performance in situations where stress has adverse consequences. In the self-organizing map, "anxiety" and "concentration", "reality", and "escape" formed the same cluster. From this, it is possible that the anxiety caused by the stress situation reduces concentration and also causes escape behavior.

Among stressful situations, situations that cause anxiety, that is, situations that are perceived as a threat to the parties concerned, are likely to experience a negative psychological state. The tension felt in such a situation can be interpreted as causing 


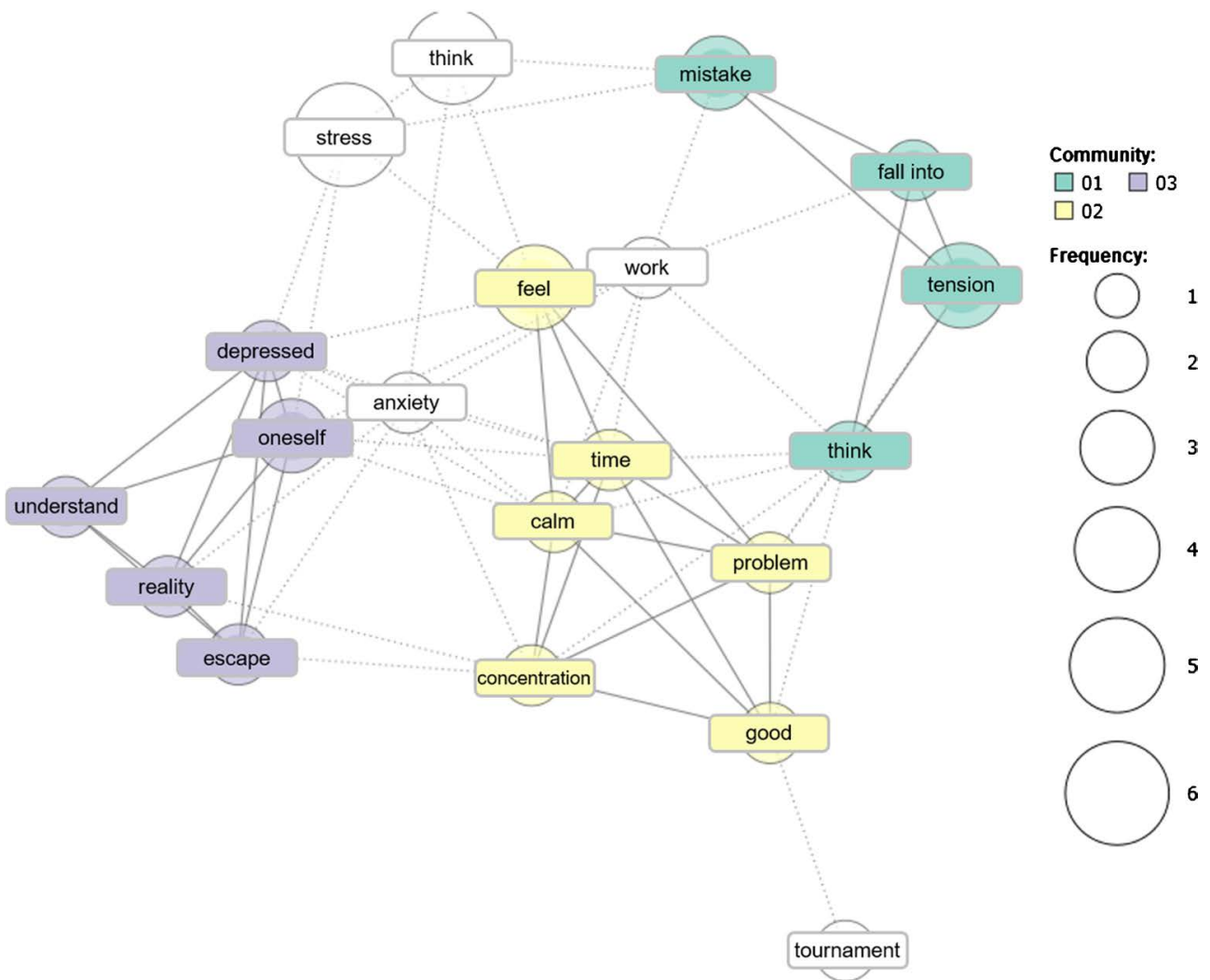

Figure 3. Co-occurrence network image based on free-description about distress.

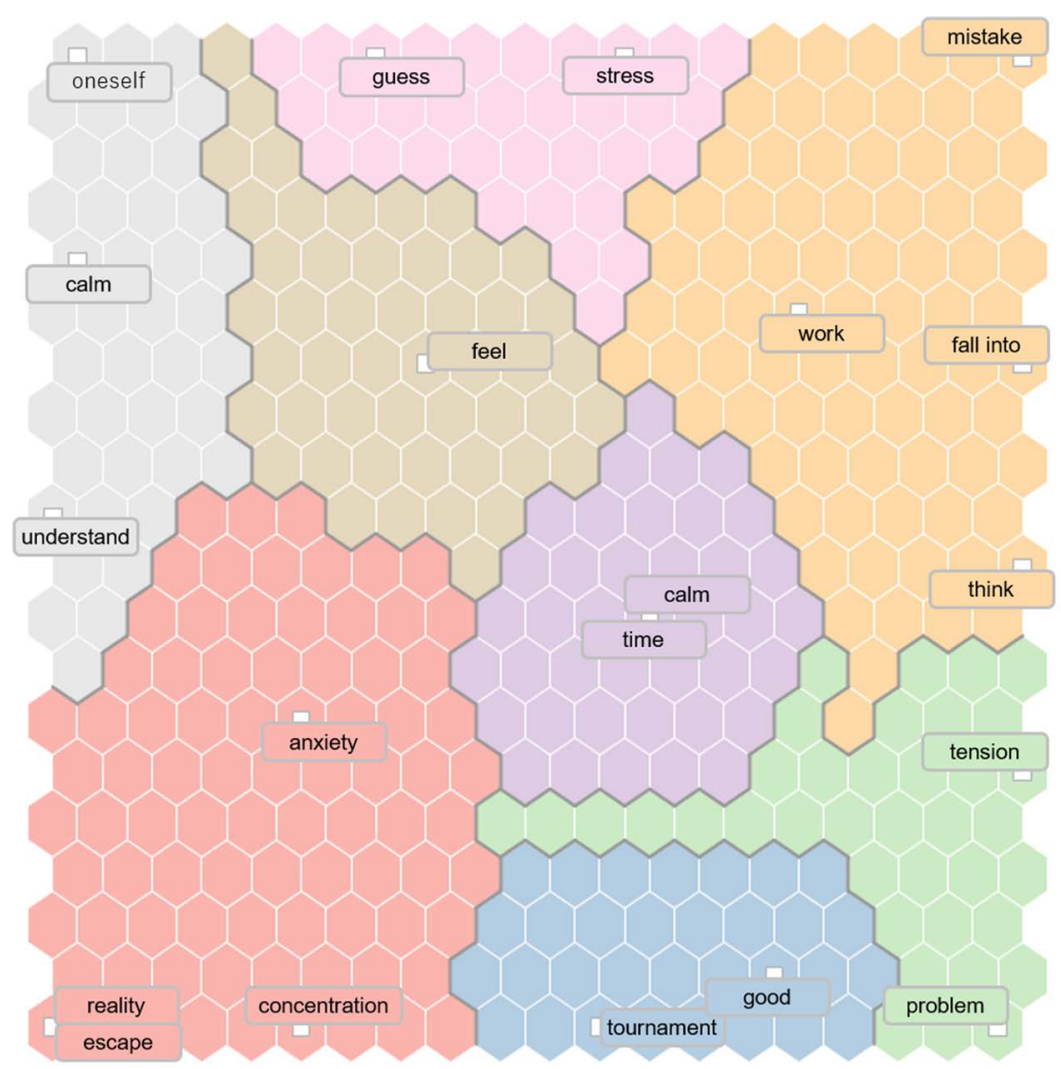

Figure 4. Self-organizing map based on free-description about distress. 
a decrease in performance in that it induces mistakes. Furthermore, anxiety causes behaviors that contrast with the above-mentioned challenge scenes, such as escape behaviors, and can be said to be emotions that characterize bad stress.

\subsection{Stress Regarded as Threat}

Figure 5 and Figure 6 show a co-occurrence network image and a self-organizing map created using free description regarding stress that is felt as a threat. In addition, Japanese-English translation for these figures was shown in Table 4.

Table 3. Japanese-English Translation for Figure 3 \& Figure 4.

\begin{tabular}{cccc}
\hline Japanese & English & Japanese & English \\
\hline 思う & guess & 落ち着く & calm \\
ストレス & stress & 問題 & problem \\
ミス & mistake & 集中 & concentration \\
陥る & fall into & good \\
緊張 & tension & 大会 & tournament \\
考える & think & 落ち込む & depressed \\
感じる & feek & 自分 & oneself \\
仕事 & work & 分かる & understand \\
不安 & anxiety & 現実 & reality \\
時間 & time & 逃避 & escape \\
\hline
\end{tabular}

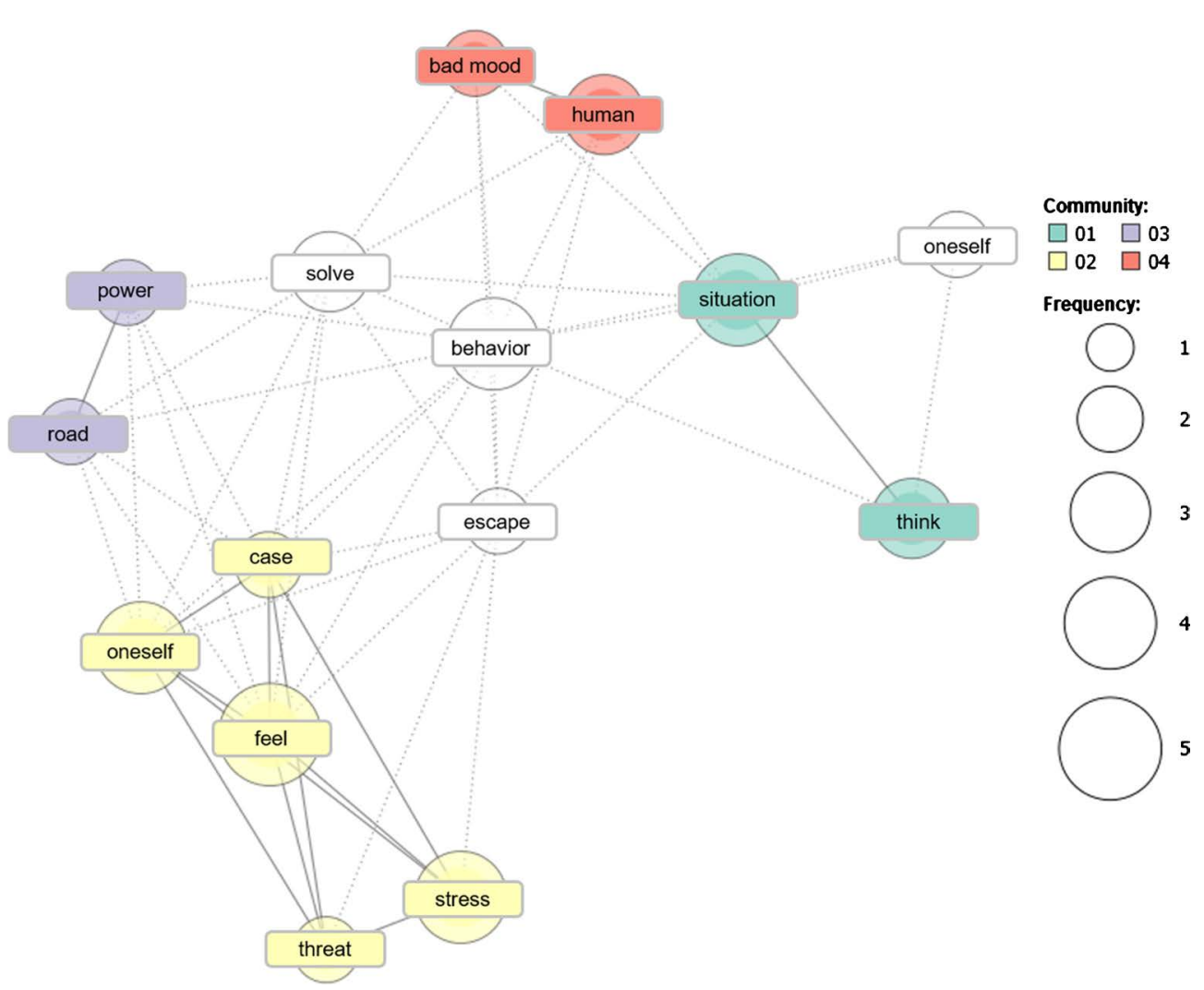

Figure 5. Co-occurrence network image based on free-description about stress regarded as threat. 


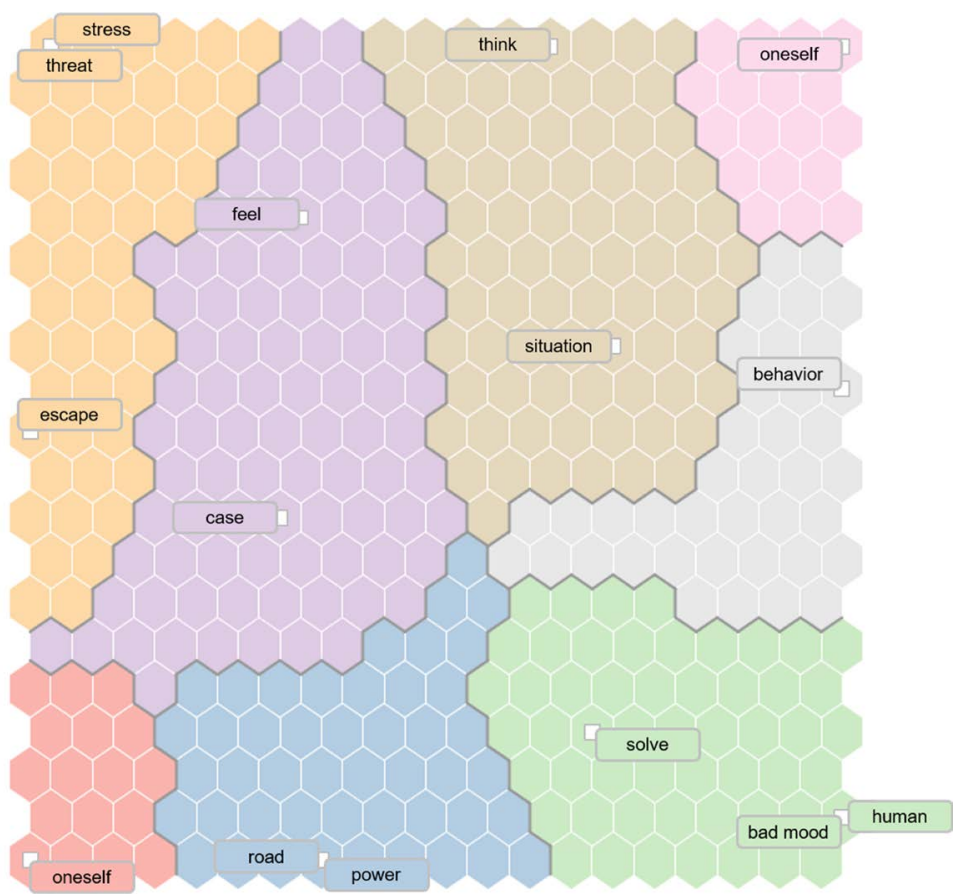

Figure 6. Self-organizing map based on free-description about stress regarded as threat.

Table 4. Japanese-English Translation for Figure 5 \& Figure 6.

\begin{tabular}{cccccc}
\hline Japanese & English & Japanese & English & Japanese & English \\
\hline 不機嫌 & bad mood & 状況 & situation & 場合 & case \\
人 & human & 自己 & oneself & 自分 & oneself \\
解決 & solve & 考える & think & 感じる & feel \\
行動 & behavior & 力 & power & ストレス & stress \\
逃避 & escape & 道 & road & 务威 & threat \\
\hline
\end{tabular}

Focusing on the co-occurrence network image and the self-organizing map, "escape" was mentioned as a word to indicate behavior in situations where "threat" was felt, and "moody" was mentioned as a word to indicate psychological state. As mentioned above, escape behavior is also seen in situations where stress has adverse consequences and is considered to be anxiety-induced behavior. The rating for stress situations is said to be "challenge" if you are confident that you can overcome the obstacles and difficulties you are facing, and "threat" if you feel down (Lazarus, 1999). In a situation where you feel a "threat", you may not be confident in overcoming obstacles and difficulties, so you may easily fall into escape behavior with anxiety. "Grumpy" is a psychological state that is measured as a type of stress response along with anger. Even in stressful situations, situations rated as "threat" are characterized by negative emotions (Lazarus \& Folkman, 1984), which is consistent with the findings of previous studies.

\subsection{Stress Regarded as Challenge}

Figure 7 and Figure 8 show the co-occurrence network image and the self-orga- 


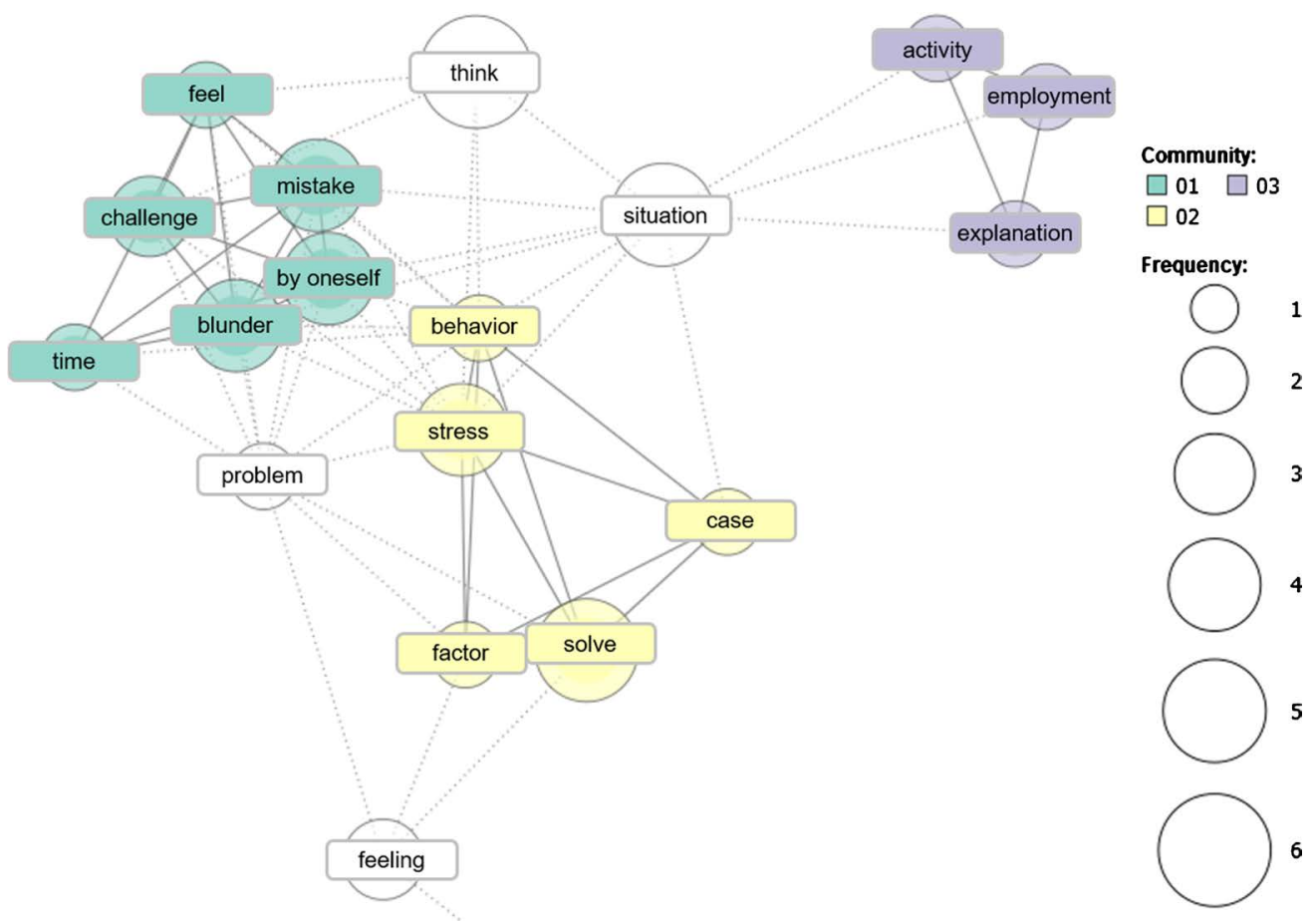

run

Figure 7. Co-occurrence network image based on free-description about stress regarded as challenge.

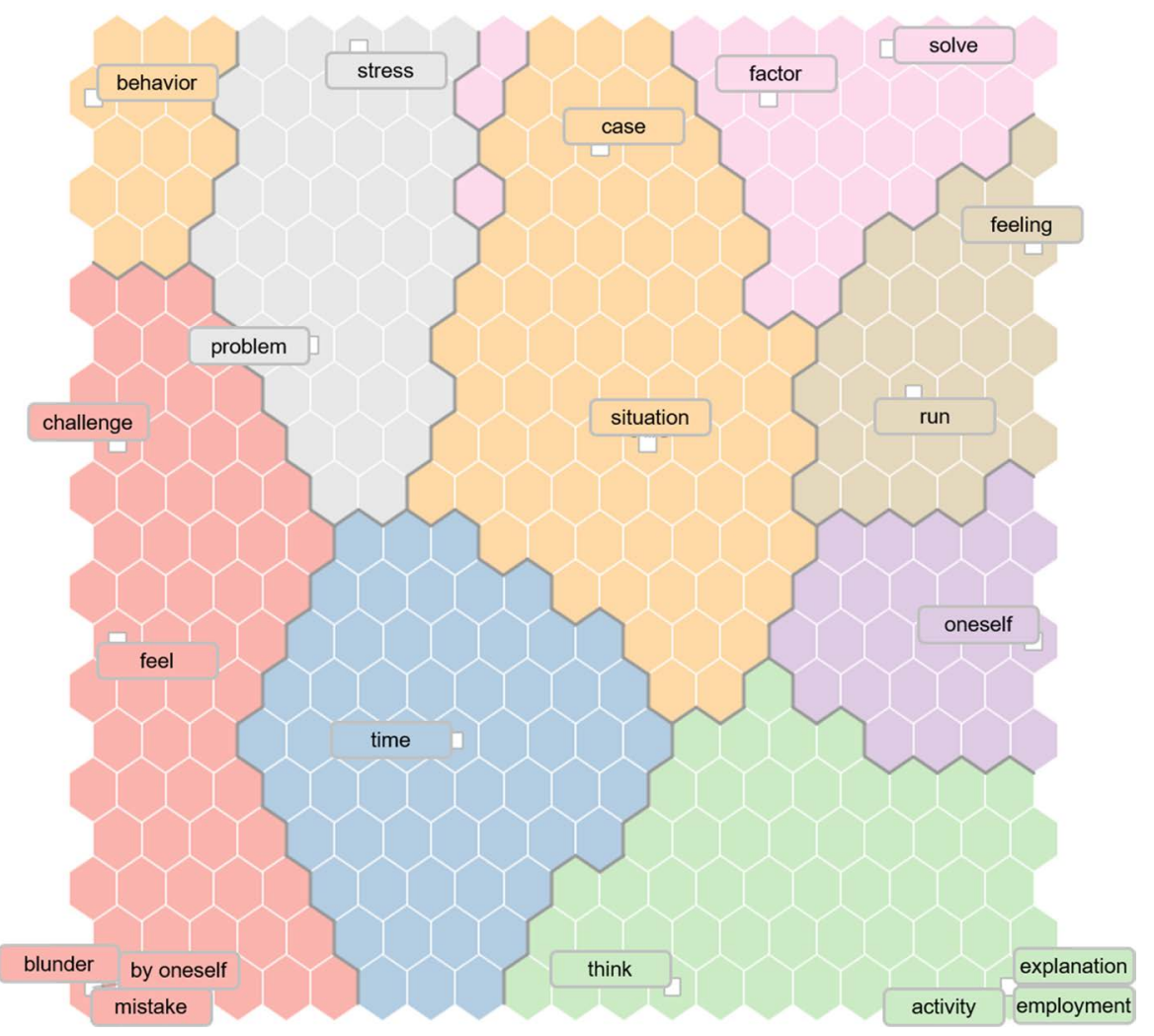

Figure 8. Self-organizing map based on free-description about stress regarded as challenge. 
nizing map created using the free description regarding the stress felt as a challenge. In addition, Japanese-English translation for these figures was shown in Table 5. Focusing on the co-occurrence network image and the self-organizing map, it is characteristic that the words "solution" and "cause" are linked to "stress" and form the same cluster.

In situations that feel "challenge," you become more motivated to solve the problems you are facing and focus on the problems that are causing stress. In this way, it is presumed that the selection of positive problem-focused coping is a characteristic of stress situations that are felt as "challenge".

\subsection{Change of Evaluation of Stress}

Figure 9 and Figure 10 show the co-occurrence network image and the self-

Table 5. Japanese-English Translation for Figure 7 \& Figure 8.

\begin{tabular}{cccccc}
\hline Japanese & English & Japanese & English & Japanese & English \\
\hline 考える & think & ミス & mistake & 原因 & factor \\
状況 & situation & 自ら & by oneself & 解決 & solve \\
活動 & activity & 失態 & blunder & 問題 & problem \\
就職 & employment & 時間 & time & 気持ち & feeling \\
説明 & explanation & 行動 & behavior & 走る & run \\
感じる & feel & ストレス & stress & & \\
挑戦 & challenge & 場合 & case & & \\
\hline
\end{tabular}

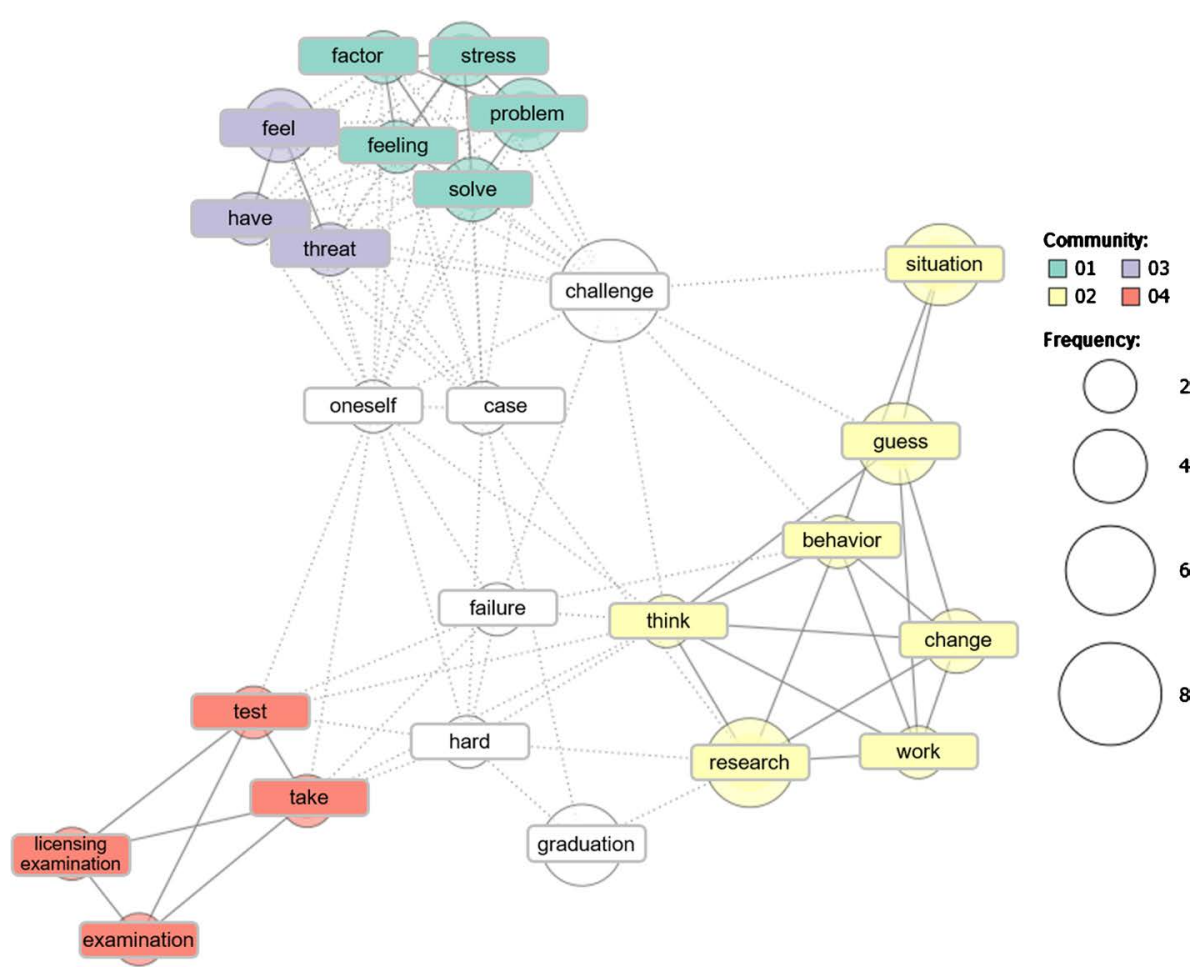

Figure 9. Co-occurrence network image based on free-description about change of evaluation of stress. 


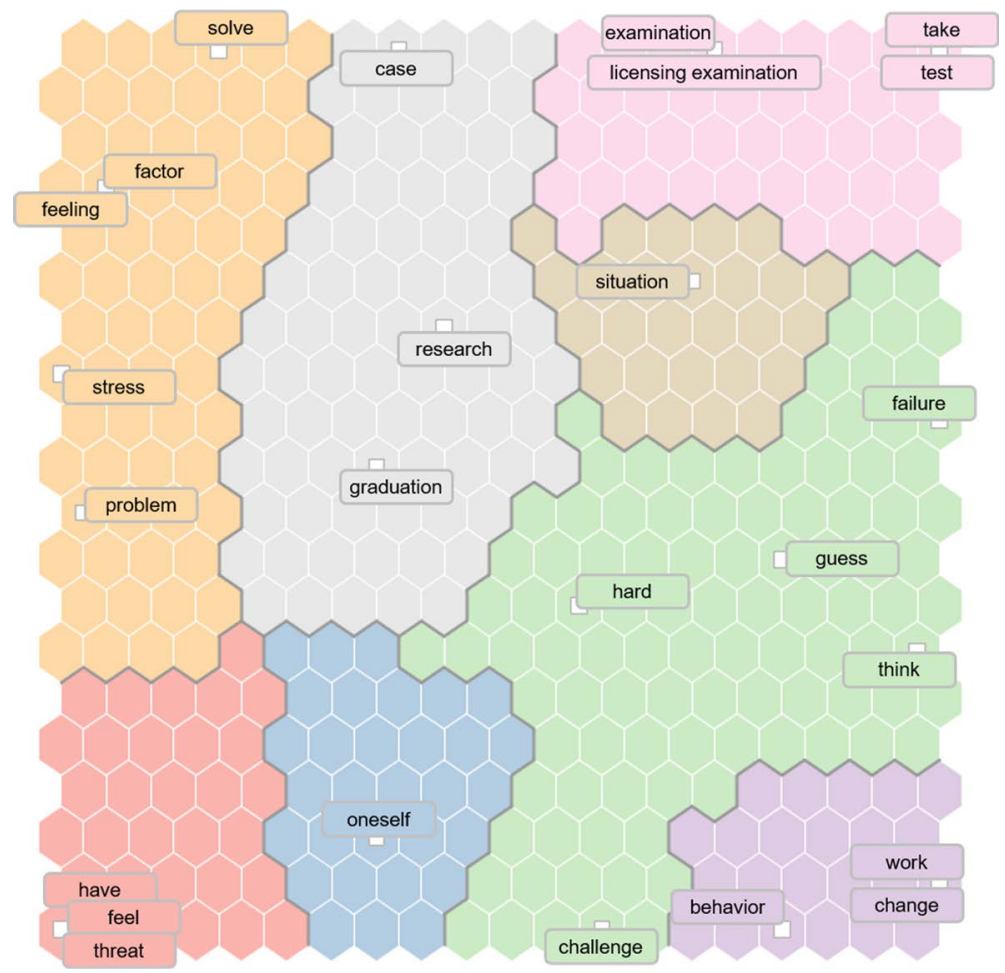

Figure 10. Self-organizing map based on free-description about stress regarded as challenge.

Table 6. Japanese-English Translation for Figure 7 \& Figure 8.

\begin{tabular}{cccccc}
\hline Japanese & English & Japanese & English & Japanese & English \\
\hline 原因 & factor & 自分 & oneself & 変化 & change \\
ストレス & stress & 場合 & case & 研究 & research \\
気持ち & feeling & 失敗 & failure & 仕事 & work \\
問題 & problem & 大变 & hard & 試験 & test \\
解決 & solve & 卒業 & graduation & 受ける & take \\
感じる & feel & 状況 & situation & 検定 & licensing examination \\
持つ & have & 思う & guess & 受験 & examination \\
脅威 & threat & 行動 & behavior & & \\
挑戦 & challenge & 考える & think & & \\
\hline
\end{tabular}

organization map created using the free description regarding the transformation of the evaluation for stress. In addition, Japanese-English translation for these figures was shown in Table 6. Focusing on the co-occurrence network image and the self-organizing map, the words "stress" and "problem", "solution", "cause", and "feeling" are linked to each other to form the same cluster. Focusing on problem solving and trying to eliminate the cause are common to thinking and actions in situations that feel "challenge." Furthermore, if a situation that was felt as a "threat" becomes a "challenge," it is suggested that there is a change in feelings. In the free description to Question 5 (Change of evaluation of 
stress), there are many descriptions about positive psychological transformation, such as reducing stress as the problem is solved, feeling "I can do it", and positively grasping the situation I am facing. In addition, some respondents cited the support of those around them, such as consulting with others and having them listen to them, as a trigger for the above-mentioned transformation. These behaviors can also be interpreted as being related to the "tend-and-befriend response (Taylor et al., 2000)", which increases the desire to connect with people under stressful conditions. The experience of gaining support and experiencing connections through relationships with those around us increases confidence in overcoming the obstacles and dangers people face and makes stress situations a "challenge" (Lazarus, 1999). It is suggested that it may be a contributing factor.

\section{Conclusion}

Analysis of the free-description obtained from the questionnaire revealed the characteristics of eustress and distress, stress regarded as threat or challenge, and thoughts, behaviors, and situations in the process of changing the evaluation of stress. Situations where stress can produce good results include challenging goals (sports games, academic exams, etc.) and the process of gaining self-confidence (daily accumulation, overcoming difficulties, etc.). On the other hand, the situations where stress has bad consequences are those that are perceived as a "threat" by the parties and cause anxiety, resulting in negative emotions, poor performance, and escape behavior. That is, "bad stress" is considered to correspond to a stress situation that is felt as a "threat". A stress situation that feels "challenge" is characterized by the way the parties think and act, such as looking at the cause of stress with the aim of solving the problem and selecting problem-focused coping. While "good stress" is often experienced in specific situations such as games and exams, it can be said that the experience of treating stress as a "challenge" occurs regardless of the situation. Furthermore, in the process of changing stress assessment from "challenge" to "threat", it was suggested that the parties may have chosen problem-focused coping and experienced positive psychological transformation. One of the reasons for this is the characteristics of thinking and behavior similar to the "tend-and-befriend response", such as obtaining support from the surroundings and recognizing the connection with the surroundings. This may increase the confidence of the parties to overcome obstacles and dangers. From the above, it can be said that even in a stress situation that feels like a "threat", the situation can be re-evaluated as a "challenge" by causing a positive psychological transformation that raises confidence in problem solving. The results of this study are considered to give new knowledge on psychological responses in stressful situations and it can be utilized for mental health education such as stress management.

The number of participants in this study was as small as eight, and the results of text mining may reflect the characteristics of the target population. In the future, it is hoped that more universal knowledge will be obtained by expanding 
the range of participants and conducting quantitative surveys.

\section{Conflicts of Interest}

The authors declare no conflicts of interest regarding the publication of this paper.

\section{References}

Higuchi, K. (2016). A Two-Step Approach to Quantitative Content Analysis: KH Coder Tutorial Using Anne of Green Gables (Part I). Ritsumeikan Social Science Review, 52, 77-91. http://www.ritsumei.ac.jp/file.jsp?id=325881

Higuchi, K. (2017). A Two-Step Approach to Quantitative Content Analysis: KH Coder Tutorial Using Anne of Green Gables (Part II). Ritsumeikan Social Science Review, 53, 137-147. http://www.ritsumei.ac.jp/file.jsp?id=346128

Lazarus, R. S. (1993). From Psychological Stress to the Emotions: A History of Changing Outlooks. Annual Review of Psychology, 44, 1-22.

https://doi.org/10.1146/annurev.ps.44.020193.000245

Lazarus, R. S. (1999). Stress and Emotion. New York: Springer.

Lazarus, R. S., \& Folkman, S. (1984). Stress, Appraisal and Coping. New York: Springer.

Ministry of Health, Labour and Welfare (2006). The Guidelines of Maintenance and Improvement of Mental Health for Workers. (In Japanese) https://www.mhlw.go.jp/hourei/doc/kouji/K151130K0020.pdf

Ministry of Health, Labour and Welfare (2019). Comprehensive Survey of Living Conditions in 2019. (In Japanese)

https://www.mhlw.go.jp/toukei/saikin/hw/k-tyosa/k-tyosa19/index.html

Selye, H. (1974). Stress without Distress. Philadelphia, PA: Lippincott.

Taylor, S. E., Klein, L. C., Lewis, B. P., Gruenewald, T. L., Gurung, R. A., \& Updegraff, J. A. (2000). Biobehavioral Responses to Stress in Females: Tend-and-Befriend, Not Fight-or-Flight. Psychological Review, 107, 411-429.

https://doi.org/10.1037/0033-295X.107.3.411

Tedeschi, R. G., \& Calhoun, L. G. (1996). The Posttraumatic Growth Inventory: Measuring the Positive Legacy of Trauma. Journal of Traumatic Stress, 9, 455-471.

https://doi.org/10.1002/jts.2490090305 